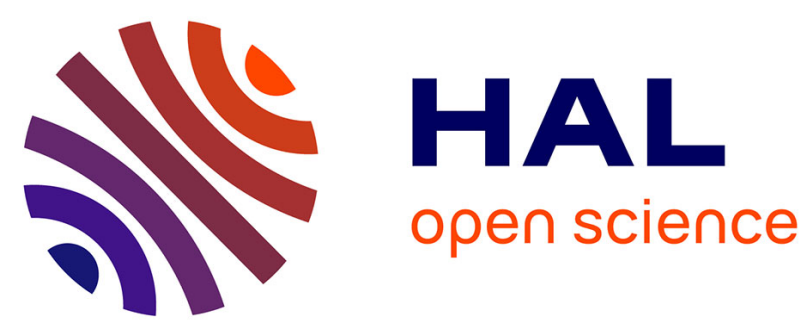

\title{
Compression and Sintering of Powder Mixtures: Experiments and Modelling
}

Didier Bouvard, Claude Carry, Jean-Marc Chaix, Christophe M. Martin, Jean-Michel Missiaen, Laurent Périer-Camby, Eric Serris, Gérard Thomas

\section{- To cite this version:}

Didier Bouvard, Claude Carry, Jean-Marc Chaix, Christophe M. Martin, Jean-Michel Missiaen, et al.. Compression and Sintering of Powder Mixtures: Experiments and Modelling. Advanced Engineering Materials, 2001, 3 (8), pp.593-597. 10.1002/1527-2648 . emse-00609789

\section{HAL Id: emse-00609789 https://hal-emse.ccsd.cnrs.fr/emse-00609789}

Submitted on 28 Jan 2020

HAL is a multi-disciplinary open access archive for the deposit and dissemination of scientific research documents, whether they are published or not. The documents may come from teaching and research institutions in France or abroad, or from public or private research centers.
L'archive ouverte pluridisciplinaire HAL, est destinée au dépôt et à la diffusion de documents scientifiques de niveau recherche, publiés ou non, émanant des établissements d'enseignement et de recherche français ou étrangers, des laboratoires publics ou privés. 


\title{
Compression and Sintering of Powder Mixtures: Experiments and Modelling
}

\author{
By Didier Bouvard, * Claude Carry, \\ Jean Marc Chaix, Christophe M. Martin, \\ Jean Michel Missiaen, Laurent Perier-Camby, \\ Eric Serris, and Gérard Thomas
}

In numerous industrial fields, materials are manufactured from powders. The most classical process consists in pouring the powder into a die and pressing in between two punches. The resulting component can be used in this state, as in the pharmaceutical industry. But, most often, for example in powder metallurgy or ceramic processing, it is submitted to a thermal treatment, called sintering, during which the particles are welded together. These two stages, compaction and sintering, have been extensively investigated in the last decades. The main physical mechanisms arising during both stages have been identified and more or less sophisticated models have been developed. However most of these studies have concerned single-component powders whereas industrial processes more frequently use mixtures of powders with different physical and mechanical properties. ${ }^{[1,2]}$ The interest of using mixtures instead of single-component powders may be to facilitate the compaction or the sintering or to create alloys or composite materials with outstanding features.

Understanding and modelling the behavior of powder mixtures require taking into account the mechanical and chemical interactions between both phases. Concerning mechanical problems, in most cases, a simple law of mixture is not appropriate. Classical models of multiphase materials hardly give better results. Accounting for the granular nature of the material is thus absolutely necessary. Relevant issues are interparticle contacts, particle rearrangement, agglomeration, phase percolation. The compressibility of bimodal mix-

[*] Dr. D. Bouvard, Dr. C. M. Martin Génie Physique et Mécanique des Matériaux INPG, UMR CNRS 5010

BP 46, F-38402 Saint Martin d'Hères Cedex (France)

Dr. C. Carry, Dr. J. M. Chaix, Dr. J. M. Missiaen

Laboratoire de Thermodynamique et Physico-Chimie

Métallurgiques

INPG/UJF, UMR CNRS 5614

BP 75, F-38402 Saint Martin d'Hères Cedex (France)

Dr. L. Perier-Camby, E. Serris, Dr. G. Thomas

Science des Procédés Industriels et Naturels

Ecole Nationale Supérieure des Mines de Saint Etienne

URA CNRS 2021

157 cours Fauriel, F-42023 Saint Etienne Cedex (France) 
tures, for example, is mainly related with the ratio of the size of particles of one phase to the size of particles of the other phase. ${ }^{[2]}$ Chemical phenomena involve more or less complex phase transformations and chemical reactions. Such transformations or reactions usually occur during sintering but they can also be generated when the material is still in the powder state, for example during milling. ${ }^{[3]}$

Most research studies in the field of powder processing at the Federation concern powder mixtures. Three examples are presented in the following, illustrating recent research studies on the behavior of powder mixtures during compression or sintering.

Compaction of pharmaceutical powders. This method has been developed to model compaction behavior of pharmaceutical powders under uniaxial stress and furthermore to explain compact properties. In pharmaceutical industry, the compacts are usually cylindrical with possibly superior or inferior spherical caps. Incomplete densification is favoured, so that the tablet dissolution rate is fast, providing that the mechanical strength is sufficient for industrial tablet handling.

Empirical models ${ }^{[4-7]}$ have been developed to describe tablet properties, such as porosity under pressure, relaxed porosity, tensile strength. Last improvements are related with the development of quasi-chemical (QC) models, ${ }^{[1,8,9]}$ which give a physical meaning to previous empirical descriptions (for example laws ${ }^{[5]}$ firstly used for metallic powders) and allow textural characterisations of tablets with parameters such as the specific surface area. Detailed QC models take into account phenomena such as grain fracture and elastoplastic deformations.

A powder of grains " $\mathrm{A}$ " exhibits porous spaces located between grains (inter-granular porosity) as well as inside grains (internal porosity). In global quasi-chemical (GQC) models these spaces are called vacancies, $V_{\mathrm{G}}$. During die pressing, when the punch goes on, the vacancies coalesce and are annihilated following the elementary reaction:

$a_{\mathrm{A}} V_{\mathrm{G}}=0$

where $a_{\mathrm{A}}$ is the reaction order (number of vacancies simultaneously annihilated). The evolution of the system is obtained by writing at equilibrium the expression of the kinetic rate for the two opposite QC reactions depending on pressure. So the porosity-pressure $n(P)$ relationship can be calculated as a function of two parameters, the order $a_{\mathrm{A}}$ and a constant $K r_{\mathrm{A}}$ $\left(\mathrm{MPa}^{-1}\right.$ unit), called the compressibility factor. Examples of the results obtained from such modelling for two pharmaceuticals products, corn starch (CS) and aspirin, are given in Figure 1.

To model the compaction of a mixture of two powders, referred to as A and B, respectively, two methods have been developed. The simplest method is based on the hypothesis of the ideal mixture. The packing density (complementary to unit of the porosity) of the mixture under a given pressure is expressed as:

$C_{\mathrm{m}}^{-1}=v_{\mathrm{A}} C_{\mathrm{A}}^{-1}+\left(1-v_{\mathrm{A}}\right) C_{\mathrm{B}}^{-1}$ $\mathrm{n}$

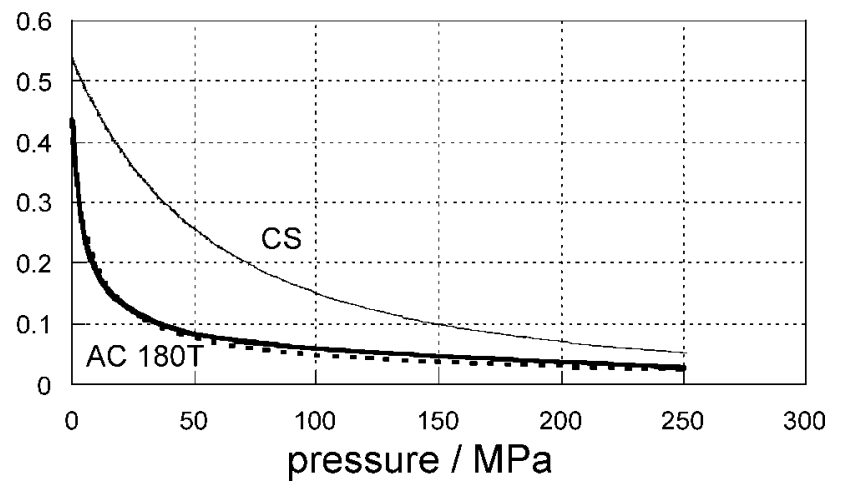

Fig. 1. Evolution of porosity versus pressure during die compaction under quasi-static conditions for CS with particle size $20 \pm 5 \mu \mathrm{m}$ and sieved aspirin (AC180T) with particle size $180 \pm 30 \mu \mathrm{m}$. Plain lines: experimental curves. Dotted lines: model curves $\left(a_{C S}\right.$ $\left.=a_{A T}=2, K r_{C S}=0.041 \mathrm{MPa}^{-1}, K r_{A C}=0.30 \mathrm{MPa}^{-1}\right)$. Experimental and model curves for CS are perfectly superposed.

where $v_{\mathrm{A}}$ is the volume fraction of phase $\mathrm{A}$ and $C_{\mathrm{A}}$ (respectively $C_{\mathrm{B}}$ ) is the packing density of powder $\mathrm{A}$ (respectively $\mathrm{B}$ ) under the same pressure. The relation $C_{A}(P)$ has been determined from experiments and modelled with coefficients $a_{i}$ and $K r_{i}$ for each powder. However, deviations from this law are observed, above all when particles of each powder have very different sizes. These deviations may be explained by two phenomena, insertion of small grains $\mathrm{A}$ in the porous network of large grains B or substitution of clusters of small particles by a large grain. Both phenomena lead to a higher density of the mixture. Models have been established for powder mixtures $^{[10]}$ and recently extended to the case of tablets. ${ }^{[1]}$

The main interest of QC treatments consists in predicting the mixture behavior by calculation with very few experimental data when the formulation is changed. The number of experiments is greater-and the quality of predictions is better-for grain insertion/substitution models applied to systems under moderate pressure and high porosity ( $n$ about 0.25) than for ideal mixture models. Nevertheless ideal mixture models are quite satisfactory for higher pressure, at which insertion/substitution phenomena cannot occur anymore ( $n$ about 0.1 ). In Figure 2 the compressibility curve of a

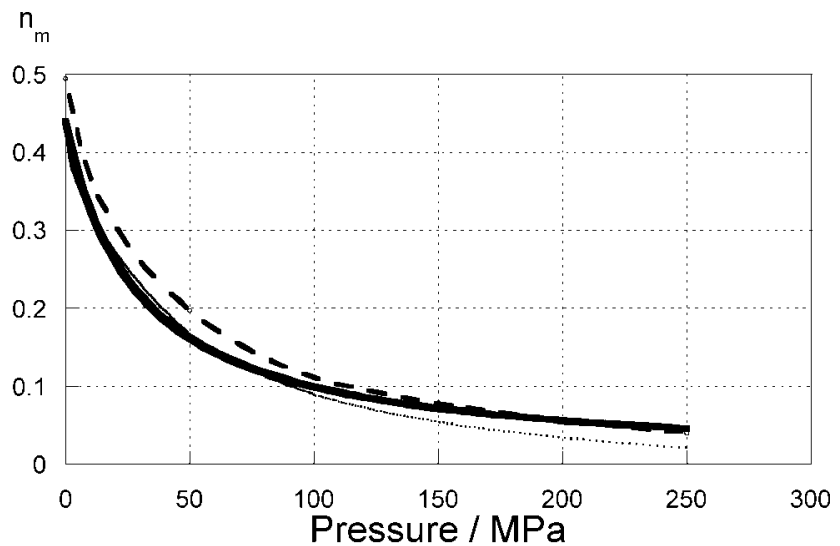

Fig. 2. Porosity vs. pressure for a mixture of CS with $40 \%$ volume fraction of AC180T aspirin. Narrow line: experimental points. Dotted line: prediction by the ideal mixture model. Bold line: GQC model $\left(\mathrm{Kr}_{m}=0.21 \mathrm{MPa}^{-1}, a_{m}=2\right)$. 
mixture of CS and $40 \%$ volume fraction of aspirin is compared with theoretical predictions.

Mechanical behavior of compacted powder mixtures under deviatoric stress. Consolidation of powder mixtures is a typical process route to obtain metal-ceramic composites with high volume fractions of hard ceramic phase. Generally, a secondary step is carried out in order to reduce porosity and/or to give its final shape to the part. This may involve extrusion, rolling or forging. Numerous authors have studied the densification behavior of powder mixtures under isotropic or quasi-isotropic pressure, ${ }^{[2,11,12]}$ whereas the effect of deviatoric and tensile stresses arising during shaping operations is poorly known. This question has recently been investigated with powder compacts containing a soft matrix powder of pure aluminum with $\mathrm{W}_{2} \mathrm{C}$ hard particles. ${ }^{[13]}$ Diametral compression ${ }^{[14]}$ and simple compression tests have been carried out with different volume fractions of hard particles ( 0 to $60 \%)$, porosity contents ( 0 to 0.25 ) and temperatures (room temperature and $\left.450^{\circ} \mathrm{C}\right)$.

In simple compression, the effect of the hard particles is noticeable both on the measured stress and on the bulk deformation of the compact. ${ }^{[13]}$ A pronounced dilatant behavior is observed. For example, the compact with the lowest relative density (0.85) and the highest fraction of inclusions $(60 \%)$ exhibits a volumetric expansion rate twice as high as the compressive strain rate in the direction of compression (Fig. 3). Even compacts with low porosity and low fraction of hard particles show significant dilatancy. This behavior is explained by the rearrangement of hard particle skeleton that generates tensile strains responsible for the rupture of con-

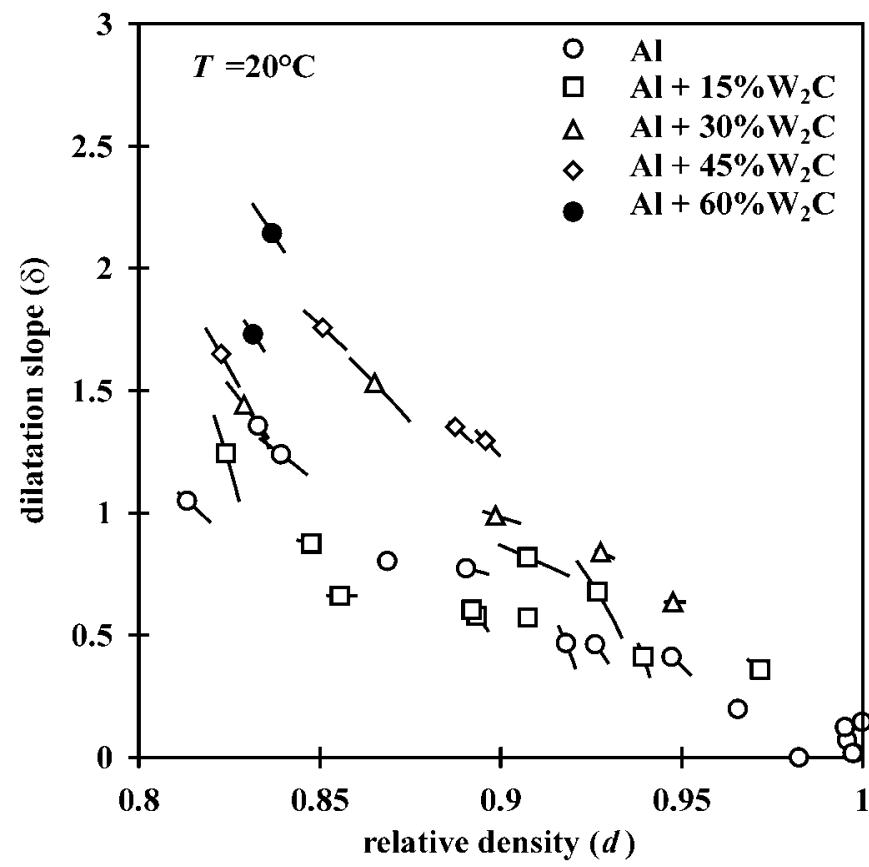

Fig. 3. Evolution of dilatation slope $\delta$ (defined as the ratio of volumetric strain rate to axial compressive strain rate) with relative density for different volume fractions of hard particles. Every mark represents a test measurement. During the deformation of the compact, the relative density is evolving. Hence the segments attached to each mark represent the evaluated evolution of $\delta$ during the test as the deformation proceeds. tacts between soft particles. When the compacts are submitted to a significant tensile strain component, as during diametral compression test, the measured strength is solely a function of the relative density and does not depend on the hard phase volume fraction (for the studied mixture, which is constituted of small soft particles and large hard particles), as shown in Figure 4. An interpretation of this observation is given in terms of the total contact area formed plastically between the soft particles during the compaction stage. ${ }^{[15]} \mathrm{A}$ simple model has been proposed relating the tensile strength to the total contact area formed plastically between soft particles during the compaction stage. ${ }^{[13]}$ The total area is calculated as a function of the fraction number, particle co-ordination number and average contact area of soft particles. It has been shown that this area is a strong function of the size ratio between the soft and hard particles.

Solid state sintering of hard metals and heavy alloys. Hard metals (e.g., WC-Co) and heavy alloys (e.g., W-Cu or W-Ni-Fe) are composite materials consisting in a "hard" refractory phase (WC or W) embedded in a "soft" metallic phase. These materials are usually processed by liquid phase sintering. However, a significant amount of densification can occur in the solid state, during heating up to the sintering temperature. ${ }^{[16,17]}$ The amount of densification in the solid state increases when the particle size decreases and nearly full densification can be achieved in the solid state for nanostructured powder mixtures. ${ }^{[18,19]}$ This is a practical motivation for more detailed studies of the mechanisms of solid state sintering of these materials. Recent studies have focussed on the possible mechanisms of spreading of the binder phase through the porous microstructure and on associated densification. ${ }^{[20,21]}$

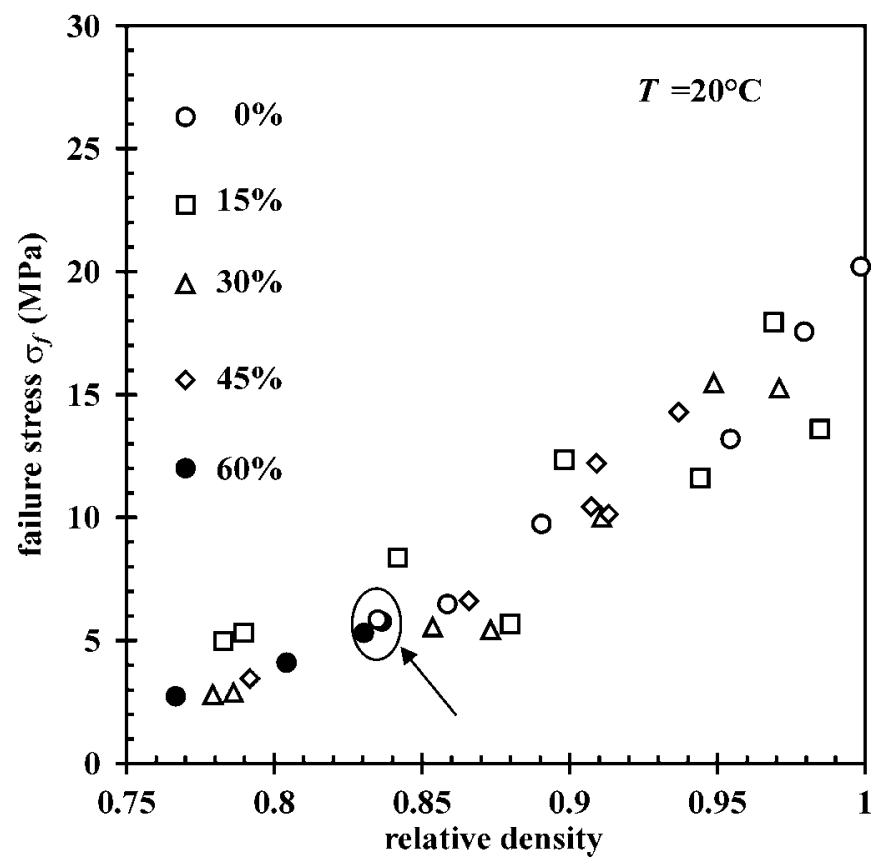

Fig. 4. Tensile stress at failure for $0 \%$ to $60 \% \mathrm{~W}_{2} \mathrm{C}$ composites at room temperature The arrow indicates compacts for very different hard particle contents $(0 \%$ and $60 \%$ $\mathrm{W}_{2} \mathrm{C}$ ) that exhibit very close tensile strengths for a given relative density. 
Analysing together the densification kinetics and the microstructural evolution can give a quantitative argument for the possible mechanisms. ${ }^{[22,23]}$ An important question is how the spreading of the binder phase can induce rearrangement of hard particles and consequently densification of the material. This point can be discussed from the evolution of the intercept length distributions in the binder phase and in the porosity (Fig. 5). These distributions represent the volume fractions of these phases having a given length in the direction of analysis. In order to compare the transferred volumes, volume fractions are normalised by the total solid phase volume, which does not vary during sintering. In $\mathrm{W}-\mathrm{Cu}$ materials sintered at $1050{ }^{\circ} \mathrm{C}$, the binder phase, which migrates into the finest porous channels, leaves large pores of about the same volume at its original place. In WC-Co materials sintered at $1200^{\circ} \mathrm{C}$, the binder phase also migrates into the fine porosity, but large pore creation is much more limited, while the volume of small pores is significantly reduced, indicating that spreading is accompanied by rearrangement and then shrinkage of the hard particles skeleton. At lower temperatures $\left(1000-1100^{\circ} \mathrm{C}\right)$, WC-Co materials behave like $\mathrm{W}-\mathrm{Cu}$ materials. The reason why spreading of the binder phase in- duces or not rearrangement is not yet clear. It may be related to the solubility of the refractory phase in the binder, which is much smaller in W-Cu system than in WC-Co system, except at low temperature. It may also depend on the amount of grain boundaries of the hard phase, which controls the rigidity of the hard particle skeleton. Work is in progress to give an interpretation of the efficiency of spreading for rearrangement and densification in these systems, in relation with parameters of the initial mixture (binder volume fraction, grain shapes, grain size distribution, mixing process...).

The behavior of powder mixtures under thermal or mechanical conditions is mainly related with their granular nature. Meaningful phenomena that have been evidenced above are insertion/substitution of particles of one phase by particles of the other phase, tensile strength of interparticle contacts, rearrangement of particles due to external or internal forces. Although main phenomena have likely been identified, much remains to do for a precise quantification of relevant material parameters (size, morphology, volume fraction of each powder) on densification behavior and mechanical properties. It should be emphasised the importance of taking into account particle rearrangement in the analysis of the de-

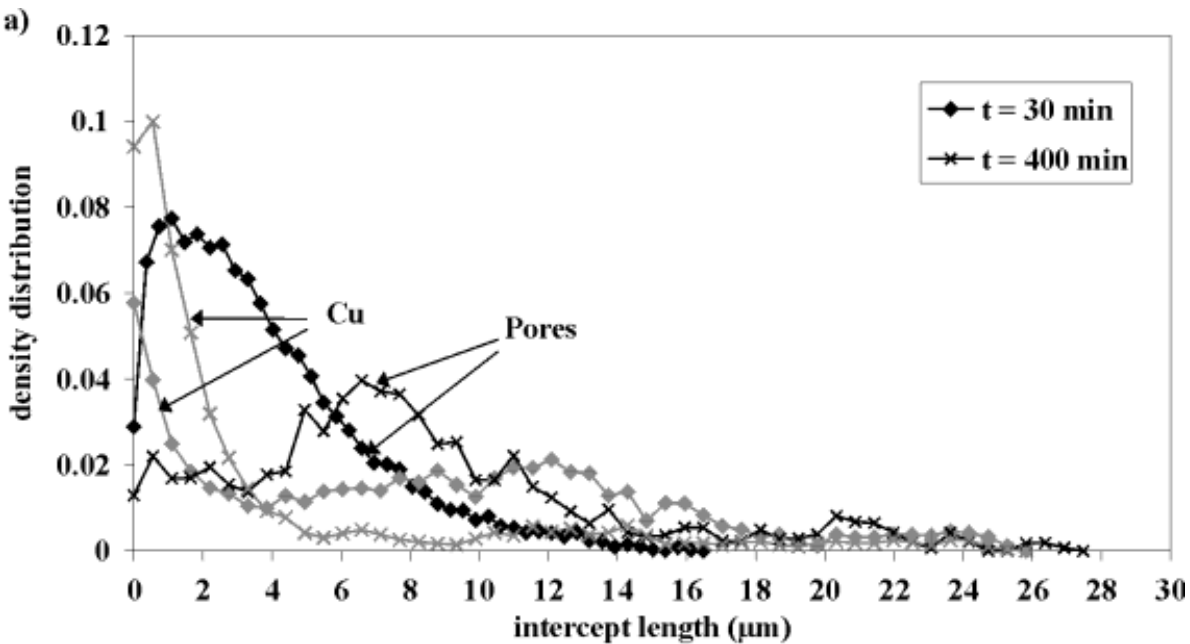

b)

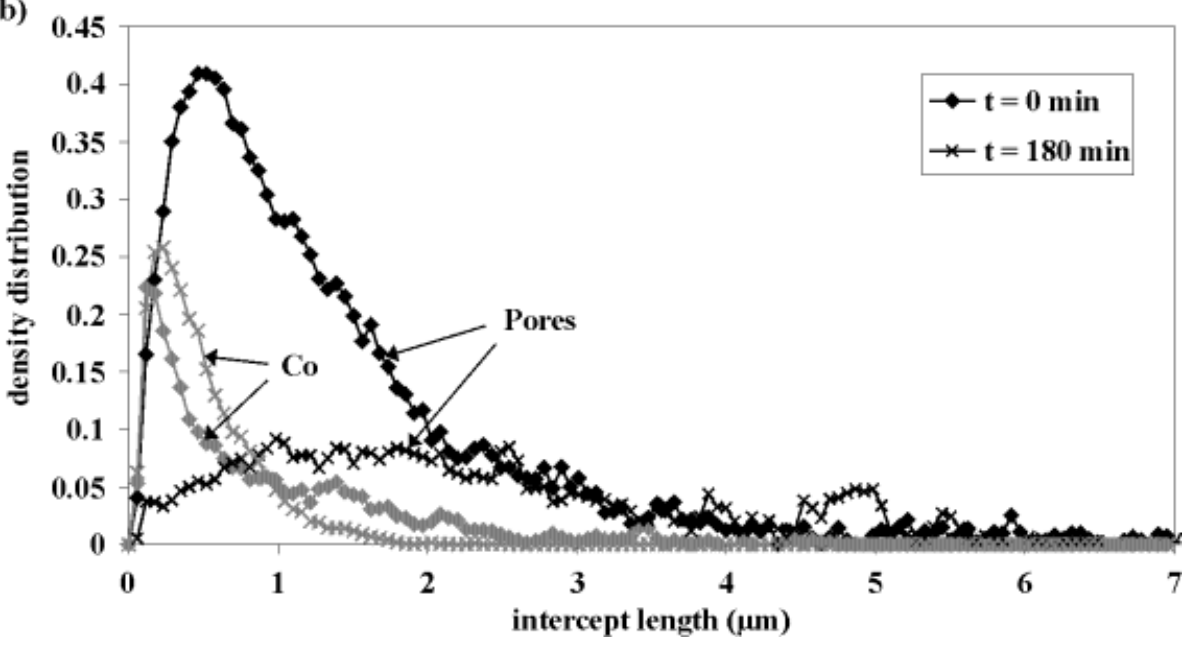

Fig. 5. Evolution of the volume-weighted intercept length distributions with sintering time: a) $\mathrm{W}-\mathrm{Cu}$ mixtures at $1050^{\circ} \mathrm{C}(35$ vol. $\% \mathrm{Cu} ; 4 \mu \mathrm{m} \mathrm{W} ; 10 \mu \mathrm{m}$ $\mathrm{Cu})$, b) WC-Co at $1200{ }^{\circ} \mathrm{C}(14$ vol. $\%$ Co; $2 \mu \mathrm{m}$ WC; $1 \mu m \mathrm{Co})$. 
formation of most powder systems, even when this mechanism is not the predominant one. ${ }^{[24]}$ While rather simple analytical models showed some predictive capabilities for classical densification mechanisms such as plastic deformation and diffusion, describing particle rearrangement indeed requires numerical models simulating the behavior of a large number of randomly packed particles. ${ }^{[25]}$

[1] J. C. Masteau, G. Thomas, J. Chim. Phys. 1999, 96, 1245.

[2] D. Bouvard, Powder Technol. 2000, 111, 231.

[3] N. Lorrain, L. Chaffron, C. Carry, J. Metastable Nanocrist. Mater. 1999, 2-6, 153.

[4] R. W. Heckel, Trans. Metall. Soc. AIME 1961, 221, 250.

[5] K. Kawachita, K. H. Lüdde, Powder Technol. 1971, 4, 61.

[6] H. Leuenberger, B. D. Rohera, Pharm. Res. 1986, 3, 12.

[7] E. Rhyshkevish, J. Am. Ceram. Soc. 1953, 36, 65.

[8] J. C. Masteau, Thèse de Doctorat, Ecole Nationale Supérieure des Mines de Saint-Etienne 1998.

[9] J. C. Masteau, G. Thomas, Powder Technol. 1999, 101, 240.

[10] R. Ben-Aïm, P. LeGoff, Powder Technol. 1967/1968, 1, 281.

[11] F. F. Lange, L. Atteraas, F. Zok, J. R. Porter, Acta. Metall. Mater. 1991, 39, 209.

[12] C. D. Turner, M. F. Ashby, Acta Mater. 1996, 44, 4521.

[13] C. Martin, O. Lame, D. Bouvard, Mech. Mater. 2000, 32, 405.

[14] M. K. Fahad, J. Mater. Sci. 1996, 31, 3723.

[15] K. E. Easterling, A. R. Tholen, Acta. Metall. 1972, 20, 1001.

[16] J. S. Lee, W. A. Kaysser, G. Petzow, in Modern Developments in Powder Metallurgy (Eds: E. N. Aqua, C. I.Whitman), MPIF, Princeton, NJ (USA), 1985, Vol. 15, p. 489.

[17] B. Meredith, D. R. Milner, Powder Metall. 1976, 1, 38.

[18] J. C. Kim, I. H. Moon, Nanostruct. Mater. 1998, 10, 283.

[19] P. Arato, L. Bartha, R. Porat, S. Berger, A. Rosen, Nanostruct. Mater. 1998, 10, 245.

[20] S. A. Haglund, J. Agren, in Sintering Technology (Eds: R. M. German, G. L. Messing, R. G. Cornwall), Marcel Dekker, New York 1995, p. 141.

[21] G.Gille, G. Leitner, W. Hermel, Z. Metallkd. 1998, 89, 73.

[22] A. M. Popa, J. M. Chaix, Science of Sintering, Special Issue 2000, 97.

[23] J. M. Missiaen, S. Roure, Acta Mater. 1998, 46, 3985.

[24] C. Legros, C. Carry, P. Bowen, H. Hofman, J. Eur. Ceram. Soc. 1999, 19, 1967.

[25] S.-M. Lee, J.-M. Chaix, C. L. Martin, C. H. Allibert, S.-J. L. Kang, Met. Mater. 1999, 5, 197. 